\title{
Integration and Cross-Border: Design of General Education Based on Multiple Fusion
}

\author{
Yuan Chen \\ Research Department, Zhejiang Radio and Television University, Hangzhou, China \\ Email: chy0501@126.com
}

How to cite this paper: Chen, Y. (2018) Integration and Cross-Border: Design of General Education Based on Multiple Fusion. Open Access Library Journal, 5: e4611.

https://doi.org/10.4236/oalib.1104611

Received: April 20, 2018

Accepted: May 21, 2018

Published: May 24, 2018

Copyright $\odot 2018$ by author and Open Access Library Inc.

This work is licensed under the Creative Commons Attribution International License (CC BY 4.0).

http://creativecommons.org/licenses/by/4.0/

(c) (i) Open Access

\begin{abstract}
General education is the development appeal of humanistic education. At the basic education stage, the general teaching fits with the physical and mental development and cognitive rules of learners at a young age. Therefore, the application and practice of general education in developed countries is relatively universal. The teaching of general education in our country started late, but the proposition that needs to be developed in the current basic education reform is urgent. At present, the development of general education is still dominated by the cultivation of general teachers. There is still a lack of integrated and complete design from mechanism to landing for general education, which is particularly lacking in the design and development of general education and curriculum. The future development trend of general teaching is characterized by informatization, interdisciplinarity, and diversity. Therefore, the integration of disciplines and practice, the integration of learners and disciplines, the teaching content and information, the technology and teaching evaluation are necessary for the integration of teaching and curriculum design.
\end{abstract}

\section{Subject Areas}

Education

\section{Keywords}

Humanistic Education, General Teaching, General Teachers, Instructional Design, Curriculum Integration

\section{The Development of General Education Should Be}

\subsection{The Appeal of Humanistic Education Idealism and Realism}

In the age of knowledge economy characterized by information, diversification, 
and globalization, science and technology and human resources have become important resources for social and economic development and global competition. Education is more viewed from the perspective of the development of national strategies, and literacy is cultivated. As an important dimension of education, students' all-round development capabilities have become a key factor in measuring education quality. Therefore, it is imperative to face the core quality of the 21 st century and to customize our education based on the skills that learners should possess in the 21st century. Students should be regarded as individuals with all-round development of complete personality, and they should develop strong adaptability in terms of character, ability, and wisdom to establish more humane education.

The literacy fundamentally breaks the original subject knowledge center and a single evaluation standard, emphasizing the integration and integration of skills, knowledge, and attitudes, and more points to the person's ability to act, that is, the person's overall ability, with practice orientation and behavior. Moreover, literacy is not simply a skill, knowledge, and attitude that can be covered, but it is the execution ability or quality of a person in a specific real situation. This requires the integration of skills, knowledge, and attitudes to be realized. The basic characteristics of the capabilities demonstrated in the process of solving problems and creating products are pluralistic, not an independent ability to exist, multi-element support overlaps each other, interweaves each other, and forms a comprehensive capacity of mutual integration. If the core literacy is directed to the level of learning, it includes the ability to solve problems in the face of complex situations, as well as the ability to use knowledge in a mixed way.

In the basic education stage, premature "subjectivization" should be avoided. The knowledge and knowledge structure of learners require lifelong learning and adjustment. The current scholastic evaluation focuses on the systematic knowledge learning, and pays more attention to the construction of a knowledge system whose basic characteristics are objectivity, systematism, and abstraction; and the future core literacy pursues the full development of learners' mind and body. The mind and body contain both mental and physical energy. Among them, the mind contains academic and non-academic factors, and academic knowledge includes the distinction of knowledge ability. Knowledge includes assessment and non-assessment content. The all-round development of learners can be divided into three dimensions: Sociality, instrumentality, and autonomy [1]. Sociality refers to the ability of learners to deal with the relationships between individuals and groups, society and countries. Instrumental means the learner's cultural knowledge and accomplishment. Autonomy is the individual's self-development ability acquired by learners, including physical literacy and psychological literacy. Socialism, instrumentality, and autonomy are all conditions, and a variety of literacy has formed an all-round development. Premature grammaticalization is not conducive to the development of learners' interest in learning. It is also inconsistent with the cognitive rules of learners in the basic 
education stage. It is not conducive to providing the basis for the learner's next-step study and realizes the seamless connection between basic education and quality education. And then the effective mode of quality education is formed.

Core literacy is the source of the entire curriculum system. How to transform core literacy into classroom teaching requires starting with reforming subject education. At present, the subject teaching is undergoing a turn. The future courses are not independent and more integrated. They are directed at the true purpose of education, life, educating people, shaping personality, and cultivating students' core qualities. In this sense, education does not regard learners as personality and culturally imperfect people. Instead, it integrates the diversity of people and the diversity of cultures into dialogues, and generates many possibilities to understand learners. This kind of education is not about control and management but about participation by the entire people. Corresponding to the appeal for the development of humanistic education, the voice of general education is rising. To cultivate talents in the future, we need to improve the appropriateness of education to develop the learners' comprehensive ability and quality, and to reflect a more humane education and teaching format.

\subsection{Research and Practice Development of General Education}

Internationally, the development of general education has become the norm. The package system originated in the United Kingdom and is prevalent in $\mathrm{Eu}-$ rope and the United States. It has been a long time since a teacher served as many or all of the teaching subjects. The contents of the general course include reading, mathematics, writing, science, sports, arts, and other courses. But the package system is not exactly equivalent to general education. The Education Bureau of Helsinki, Finland, announced that from November 2016 to 2020, it began to abolish course-based education in primary and secondary schools and instead adopted an attempt to teach students in real-life scenarios [2]. The Phenomenological Teaching Method fundamentally subverts the existing teaching methods of the subject. The purpose of education is not to impart knowledge, but to enhance the cognition of learners and form self-recognition as the core of education. But the "phenomenon of teaching" is not equivalent to general education. General education is not equivalent to a single curriculum integration, nor is it completely equivalent to multi-disciplinary teaching and general teaching. At present, there is no definition of a unified definition because general education relates to the overall setting in the context of curriculum reform, which means that In the reform of education quality evaluation, the academic community still needs to further clarify the concept of general education, clarify the connotation and extension, and contribute to the theoretical development of general education. The promotion of general education at home and abroad is based on the training of teachers. Deakin University of Australia has redesigned the primary school teacher education curriculum [3]: (1) Basic disciplines, pri- 
mary education, and professional learning modules. Some form the core curriculum structure of primary school teacher education. Among them, subject basic courses cover the contents of science, mathematics, literature, and other disciplines; primary education courses cover all courses in the elementary school, and each occupies different credits according to the proportion of courses; professional learning module mainly refers to teacher education courses, from education Theory to guide practice has achieved the unity of theory and practice, covering all the various elements needed to implement professional skills of teachers. This kind of comprehensive setup for primary school teacher education provides some reference for the cultivation of primary school teachers in China.

On the other hand, the development of China's general education is only an initial stage. At present, the primary school teaching model that is more commonly adopted is still divided into teaching. Since 2001, the Ministry of Education of the People's Republic of China has begun the deployment of a comprehensive curriculum program and issued the "Outline for the Reform of the New Basic Education Curriculum (Trial)" [4]. It is planned to add a comprehensive curriculum at the primary school level and focus on the integrated curriculum. The purpose of the teaching method is to reduce the number of elementary school subjects and reduce the academic burden on learners. This requires changes in the current status of over-construction and lack of integration of curriculum structures in the basic education stage. In the elementary school stage, comprehensive courses are set up and the comprehensive curriculum is used for teaching. In September 2012, in the "Opinions on Deepening the Reform of Teacher Education" promulgated by the National Ministry of Education and the National Development and Reform Commission, the statement of "Complete Training Model for Primary School Teachers" was formally proposed [5]. Then, the four ministries and commissions of the Ministry of Education reiterated in their "Opinions on Vigorously Promoting the Building of the Contingent of Compulsory Education Teachers in Rural Areas" [5] to expand the opinion on the "university primary school teacher training scale". In 2014, the "Opinions on Implementing Outstanding Teacher Training Program" [5] of the Ministry of Education continued to emphasize the "practical needs of primary education, focusing on exploring the general primary school teacher training model" approach. From the perspective of policy development, China's The reason for education is to make up for the lack of basic education in rural areas, but its development direction is toward the development of excellent teachers. The general teacher has become the tough goal of teacher education reform. According to the actual needs of primary education, the exploration of the general school teacher training model will be the focus of future work. The promotion of the policy is aimed at cultivating an excellent general discipline with superior education and teaching capabilities and capable of meeting the needs of multi-subject education in primary schools.

Under the guidance of policies, in recent years, research results on gener- 
al-purpose primary school teachers in literature research projects have suddenly increased in recent years, reflecting a certain degree of policy interest. The practice of general education is still in the exploratory stage. The education research of the department focuses on the development of the localization practice of general education. In these studies, the understanding and understanding of general education are continuously deepening: focus will be placed on the implementation of quality education, the development of multi-disciplinary teaching, the transformation of education and teaching methods, and the recognition of the relationship between general education and the development of learners' abilities. Recognition. Based on the actual needs, the cultivation of general teachers has always been the focus of research and discussion, but the discussion of the general course is rare. Therefore, this research will focus on the implementation of general teaching, and discuss the multi-integration trend and integration form of general education under the information background.

\section{The Future Development Trend of General Education}

\subsection{The Challenge of Internet Teaching}

The current rapid development of educational technology has promoted the generation of an educational environment in which the combination of networking, digitization and intelligence has been organically integrated. The infinitely open learning platform has communicated all educational resources. Modern information technology has given birth to the renewal of education and teaching methods. New ones such as these Things have brought many new opportunities and challenges for teaching. The face of endless flood of information, drastically accelerated social mobility, accelerated development of science and technology, unpredictable virtual world, and such new things have brought many new opportunities and challenges for teaching. The information elements under the conditions of informatization are more abundant and far-reaching, and the learning methods, results display, process communication, and problem solving of curriculum integration need to be completed collaboratively. From the perspective of content adaptability and adaptability of the curriculum, information-based teaching Tools can express a variety of structure and level of knowledge, which is conducive to the integration of the curriculum and cross-border, but also conducive to the use of a variety of teaching resources. The new teaching concepts, teaching theories, and teaching methods that are supported by information technology are gradually popularizing and guiding various fields and links in education and teaching activities. The rise of new technologies such as makerspace, wearable technology, adaptive learning technology, and internet of things technology has had a disruptive effect on education and teaching. The rapid growth of technology has intensified the complexity of education and promoted the innovation of teaching methods and methods. . New teaching paradigms, such as flipping classrooms and mooc, are widely used, and intelligent teaching forms in the future will give great support to general education. 


\subsection{Interdisciplinary Cross-Infiltration}

With the increase of new disciplines and cross-disciplines, the interpenetration of various disciplines, the degree of connection has deepened. The intersection of disciplines is an important mechanism for the direct integration of traditional disciplines and modern disciplines. It has the potential to influence skills, character and meta-learning, and also has an important impact on knowledge transfer. The interdisciplinary approach to knowledge construction helps learners establish connections between concepts and further advance learning. The fusion of disciplines triggered by scientific development has stimulated the development of collaboration-oriented interdisciplinary teaching. As a result, at present, in the international community, general education based on curriculum integration has been widely developed in the United States, Britain, and other countries, and it has been continuously improved and popularized, and it has become normal. In recent years, the hurricane STEM curriculum has been a wonderful case of transdisciplinary education. Cross-border and integration is the development direction of future courses. It is represented by practice as a carrier and bridge, and with a deeper and more diverse design and exploration as means to integrate multi-disciplinary and integrated teaching to solve practical problems in life. In order to form a productive quality course.

\subsection{Diversification of Teaching Methods}

The new curriculum reform in basic education in China advocates pluralistic reforms in teaching methods: It is embodied in the free, flexible and effective use of information technology in the learning process, online teaching, mixed teaching, online education, cloud education, gambling learning, virtual learning community and reality classroom Education and teaching methods such as organic integration continue to be introduced. The existing teaching is organized and arranged according to the logic system of knowledge, not according to the learner's cognitive logic, emphasizing the integration of knowledge in the form of deep learning in the way of learning and cognition. The concrete manifestation is fragmentation of information integration and deep processing of information. Deep learning does not value knowledge, but emphasizes the linking of knowledge.

Therefore, general education requires teachers to skillfully select knowledge, learning strategies and social skills, reconstruct the representation of the content organization system, vigorously develop digital learning resources that meet the learner's cognitive laws, and adopt flexible and diversified teaching methods. And means to ensure teaching effectiveness. General teachers can guide learners to obtain analytical methods from different perspectives by demonstrating the form of knowledge in different subject areas, and to understand the application value of these methods. In learning, general education does not emphasize the memory of knowledge, but highlights the learners' thinking, ability, and temperament training. 


\section{The Goal Value of the General Curriculum Is Reflected}

The general education is taught in the form of curriculum integration, and its emphasis on curriculum and the redesign of diversity. Cross-border and integration is the development direction of future courses. It is represented by practice as a carrier and bridge, and with deeper and more diverse design and exploration as a means to integrate multi-disciplinary cross-learning and solve practical problems in life. Create a generative and quality curriculum. The goal is to develop the learner's comprehensive ability and quality, to reflect a more humane form of education and teaching, and to represent the learning and transformation process from knowledge-based learning to knowledge essence.

General teaching involves deep design of the four dimensions of education: knowledge, skills, character, and meta-learning:

\subsection{Create Value}

Creative literacy education is not only the acquisition and reproduction of knowledge, but also the learning ability of memory-type thinking and method. Emphasizing the integration and comprehensive use of knowledge, teachers make flexible and flexible decisions by adapting, integrating, and expanding in accordance with uncertain situations, and reprocess and recreate the curriculum to make it more in line with the development needs of students and schools. . Learners must constantly transform and innovate in communication and interaction, and become active and active learners.

\subsection{Practical Value}

General teaching is not only for cognitive memory or skills training, but is also integrated with the living situation and connected to the specific practical teaching in the dynamic social life. Learners do not lose their learning motivation because they are separated from the real world. It is necessary to link learning with real-world problems, seek the authenticity of the learning environment in real life and society, face the learner's perceptual experience, set the way of problem situations, and understand the significance of learning in communication and interaction.

\subsection{Cognitive Value}

Interdisciplinary knowledge construction helps learners to establish connections between concepts and then advance deeper learning. Learners can comprehensively use the content of various disciplines to think and judge instead of focusing on simple knowledge and memory. Instead, they focus on the use of knowledge and skills to solve real-world problems, including thinking, judgment, expression, and personality [6]. Effectively improve the learner's meta-learning ability.

\subsection{Emotional Value}

General teaching must have internal drive to stimulate learners' learning, con- 
form to the development of learner's nature, pay attention to the learner's heart and happiness, and face up to the personal needs and learning needs of students' development, so that learners can feel the significance and achievements of learning. Helping learners accept and internalize values and spiritual ideas, gain the ability to understand the world, practice, cognition and emotion must all run through the teaching process.

\subsection{Literacy Value}

Literacy is the ability and character formed by learners in the learning process of disciplines. Literacy can not be separated from the support of subject knowledge and discipline systems. The structure of literacy includes various dimensions, levels, and levels. A variety of literacy is conducive to the formation of interdisciplinary links and softening of subject knowledge boundaries. It helps the learners to digest the fragmented knowledge and instill knowledge of the curriculum as a whole. It provides learners with a broader perspective and develops more comprehensive and comprehensive talents.

\subsection{Technical Value}

The integration of information technology and curriculum is becoming a hot issue in current curriculum reform. Integrating computer technology into various disciplines has changed the traditional teaching methods. Teachers can implement curriculum integration through such methods as information retrieval, multimedia presentation, teacher-student interaction, and student independent inquiry learning on the basis of proficiency in technology. From the point of view of the integrated target value, the deep integration of information technology and education not only provides strong support for the development of the current teaching model, but also is the development trend of future courses.

\section{The Multi-Integration of General Education}

General teaching is based on the physical and psychological characteristics of learners and cultivates their in-depth cognitive abilities based on the learners' qualities. Through learning, learners organically connect the knowledge of various disciplines, think independently, analyze each other in depth, and integrate different knowledge so as to cultivate healthy personality and psychology. General teaching realizes the integration of multiple disciplines, the integration of teaching and learning, and the deep integration of educational technology. It is a multi-discipline integrated teaching form.

\subsection{Multidisciplinary Integration, Realizing the Integration of Discipline and Practice}

4.1.1. General Course Is the Integration of Multidisciplinary Knowledge General subjects need to have a holistic view of the subject: 1) Each subject needs to be streamlined and integrated, the content of the course needs to be deepened, and organically combined theory and practice; 2) Driven by problems, through 
collaborative activities, In the real situation, the study of learning and the application of knowledge are carried out to restore the overall vision of the society. 3 ) The general education needs to coordinate the design of multiple disciplines. In the specific curriculum, there should be core courses and derivative courses. The core curriculum is the core of the entire curriculum. It is integrated and can connect related courses in series. Derived courses are prone to happen. They are the attachments to the core curriculum and they are also basic.

The general knowledge is conducive to the transfer of knowledge, which is mainly reflected in the knowledge acquired from processing the source task, applied to new target problems, and the knowledge of the source scene is migrated to the target task or scene. The curriculum design of the general course means that the teaching objectives, course setting, teaching evaluation and other elements of the course are systematically considered and operated. Teachers need to break the boundaries of thinking and use a connected, divergent, holistic, and dialectical perspective to study the relationship between various factors in the education process. The free integration of disciplines can be achieved by freely transforming the concepts of disciplines in different fields, linking daily life with the real world. General education is committed to the overall development of people. It teaches students to use different ways of thinking to learn knowledge, to understand more profoundly more knowledge, concepts and methods, and to use critical thinking to solve practical problems. Construct a general cognitive view for learners.

\subsubsection{The General Course Is a Continuously Generating Teaching Process}

The general course changes the internal logic of knowledge presentation and integrates the various disciplines according to the teaching situation. It is easier for learners to construct their own disciplinary system and grasp the relationship between disciplines in the whole course of study. Therefore, general education emphasizes the active construction of knowledge by the main body of learning. Students actively participate in the value generation of activities and achieve meaningful teaching. Teachers should pay attention to the individual needs of the learners and constantly adapt to the changing needs of students, and at any time to adapt to the needs and differences of students, and according to the practice and situation changes, the subject of the subject needs to be analyzed, the key content analysis, selection of learning content, therefore, Teaching content is constantly changing and flexible.

\subsection{The Conversion of Teaching and Learning to Achieve the Integration of Learners and Disciplines}

\subsubsection{Learner-Centered Curriculum System}

Discipline teaching emphasizes the orientation of knowledge center, while general education emphasizes the orientation of ability and quality. It adopts a "learner-centered" curriculum system to meet the development needs of learners' diversification, and aims at interdisciplinary comprehensive practice activi- 
ties. Learning in the sense that learners autonomously determine and reconstruct the learning framework, education in this sense does not regard learners as personality and culturally imperfect people, but instead integrates the diversity of people and diversity of culture into dialogue. There are many possibilities to understand learners. This kind of education is not about control and management, but about participation. Therefore, general education is teacher-oriented and student-centered. The leading role of teachers is reflected in the transformation from executive courses to development courses, from the transfer of knowledge to the introduction of knowledge. The traditional teacher-centered teaching model is being challenged. General teachers should become more organizers of learning activities, control the entire learning process, and need to help design appropriate problems and grasp the direction of teaching and guide learners' learning direction. To play a powerful role in providing learners with strong learning support, which requires teachers to master a certain amount of complex knowledge and teaching ability.

\subsubsection{Reconstruction of the Teaching Process}

General teaching is problem-oriented teaching. In classroom teaching, from the subject center to the student's main body's return learning method, from receiving learning to inquiry learning transformation, the teaching process is centered on learners' active exploration. In the teaching process, learners continue to connect with others, with knowledge, and the learning environment, and continue to innovate in the process of connection. Therefore, in general education, it is necessary to emphasize the learner's learning subjectivity and creativity in the learning process, as well as the teacher's activity organization ability and curriculum design ability. Learners construct knowledge in general learning and achieve learning objectives through active and conscious acquisition of materials. Teachers are the organizers and commanders in the process of general teaching. The dominant role of teachers is to optimize the implementation of teaching activities. General teachers need to be immersed in the study and life of the learners. They must follow and observe the learners in order to establish an accurate understanding of learners' personalities and establish a harmonious teacher-student relationship. Amicable and harmonious teacher-student relationship can promote the transformation of the collective goal of teaching into the individual learner's intentions, and transform the teaching activities of the group into individual students' conscious behavior. In the classroom, the synchronization between the subject participation process and the activity process is best achieved. The effect of teaching, so as to achieve the purpose of teaching activities to promote student development, to ensure the optimal development of each student in teaching.

\subsection{Combining Informatization to Realize the Integration of Teaching Content and Information Technology}

\subsubsection{Informatization of Teaching Environment}

General teaching needs to motivate students' metacognitive systems. Learners' 
individualized independent learning, including information collection, comprehensive subject knowledge experience, continuous inquiry process, project-based dialogue and collaboration, etc., all need informationization. Teaching environment support. With rich information and unlimited connections, the traditional physical space and resource space are changed. Each step of the learning process reflects the learner's subjectivity.

\subsubsection{Openness and Innovation in Content and Form}

The in-depth integration of information technology and general curriculum content breaks through the linear expression of traditional courses. The information-based teaching environment is more conducive to the fusion of general teaching content, such as the non-linear connection and transformation of subject concepts, as well as practical activities. Design and implementation. The performance of the course is rich media, strong interaction, and flexible adaptability. Through the use of appropriate teaching software, the boundaries of traditional thinking can be broken and new cognitive muscles can be produced. For example, learning analysis, and the large-scale open education curriculum with its own equipment all provide support for future learning, and various types of social media such as WeChat. It is possible to integrate teaching into life by summoning different time, space, characters, and possibilities. These have created disruptive innovations in teaching methods and instructional design, and they also represent future trends in curriculum development.

\subsection{The Use of Data Analysis, Focusing on the Integration of Teaching and Evaluation}

\subsubsection{From Single Score Evaluation to Formative Big Data Evaluation}

The existing teaching evaluation is still based on the standardized evaluation method of exam-oriented education, and it is easy to produce a "separated evaluation" of the overall quality of learners resulting from the evaluation of a single score, which has a great negative impact on the development of learners' personality. . General education is devoted to the development of the overall quality of human beings. Its evaluation methods are not limited to the acquisition and reproduction of knowledge, but also formative evaluation of learning activities. Therefore, the evaluation of learners in general education is more comprehensive, but it is also more complicated. General education should aim at the development of students' comprehensive ability, from a single score evaluation to formative big data evaluation, including all records of the learner's learning process. Therefore, it is necessary to construct a learner-centered curriculum teaching real-time evaluation system based on data analysis, and to personalize the unstructured data of students based on big data.

\subsubsection{Establish a Feedback Mechanism}

Through the adaptive diagnosis of generative learning data, we can predict the quality of teaching assessment, make detailed analysis of teaching strategies, and 
constantly optimize the teaching process and teaching objectives to improve classroom teaching satisfaction. The purpose of evaluation feedback is to personalize learning and teaching so that learners can use the information that best suits their needs.

\section{Conclusion}

General education is the form of education that develops from exam-oriented education to quality education. In general education, teachers play a leading role. Teachers are full professors and form a close relationship with learners. The learning community is also the designer and implementer of the curriculum. It fully embodies the teaching objectives and the main teaching purpose of the general education in teaching implementation and curriculum design. General teachers and general teaching are mutual factors that are interrelated and mutually causal. The research object of this research is the multivariate fusion trend and fusion form of the general teaching under the information background, but it is also closely related to the development of the ability of the general teacher. In general education, we should base our efforts on the development of curriculum integration among general teachers to improve the ability of general teachers to grasp the implementation of the general classroom to promote the development of general education practice.

\section{Fund Project}

This is one of the research achievements of the Zhejiang University's Visiting Scholar Professional Development Project for Teachers of Higher Education in 2015.

\section{References}

[1] Li, Y.L. (2016) What Kind of Basic Education Can Adapt to the Future? Growth, No. 33.

[2] Yang, Z.K. (2017) There Are Three Major Changes to the Future Education in the Context of Informatization. http://learning.sohu.com/20170107/n478023238.shtml

[3] Li, Y.F. (2015) Enlightenment of Curriculum Design for Elementary Education at Deakin University in Australia on Teacher Training. Teacher Education Forum, No. 1, 39-44.

[4] Zhang, R. (2015) Research on the Cultivation of General Primary School Teachers. Luoyang Normal University, Luoyang.

[5] Zhang, S.X. Research on the Focus of Teacher Training in Primary School and Its Countermeasures. Educational Development Research.

[6] Zhong, Q.Q. (2016) Curriculum Development Based on Core Literacy: Challenges and Questions. Global Education Prospects, 45, 3-25. 